\title{
Forced-choice form recognition during binocular rivalry'
}

ROBERT FOX AND RONALD CHECK

VANDERBILT UNIVERSITY

Forced-choice form recognition thresholds were obtained for both eyes concurrently under rivalry suppression and nonsuppression and for a nonrivalry control condition. Suppression produced a significant decrement in recognition; nonsuppression and nonrivalry did not differ significantly. These data support the hypotheses that suppression represents an inhibitory state and that nonsuppression represents a state of normal visual sensitivity.

Binocular rivalry occurs when each eye receives dissimilar stimulation and the monocular views are alternately phenomenally suppressed for several seconds. Recent investigations of the suppression process in binocular rivalry (Fox, 1963) have revealed that test stimuli presented to the eye during suppression phases a re attenuated relative to nonsuppression phases. Further, suppression is nonselective in that many classes of test stimuli are equally impaired by the suppression state (Fox, 1965).

In this experiment the effects of suppression and nonsuppression upon a forced-choice form recognition task are measured for the case where both eyes are tested concurrently. In addition, the sensitivity of the eye during nonsuppression is compared with a nonrivalry viewing condition.

Method

Subjects. Two male experienced psychophysical observers served. Both Ss were right-eye dominant (as measured by the Miles funnel test) and had normal uncorrected vision.

Apparatus. The lighting and timing systems of a three-field tachistoscope (Scientific Prototype Manf. Corp., model H) combined with a Wheatstone-type stereoscope comprised the basic apparatus.

The left and right eye fields each consisted of a $7^{\circ}$ white Plexiglas square transilluminated by incandescent lamps. To facilitate fusion of the squares, two black stripes were located along the vertical edges of each square. For the rivalry condttions the rivalry targets were located in the center of each square. Each target consisted of a $1^{\circ} 20^{\prime}$ square formed from 17' black stripes. The interior of the left field target was covered with a green acetate filter (Edmund Scientific Co., theatrical filter), the right field with a similar red filter. Diagonal black 3' lines were placed over the colored interiors of each target; between the left and right targets the line sets were oriented perpendicularly to each other.

The nonrivalry condition involved pairing one rivalry target (green in the left field, red in the right field) with a blank contralateral $7^{\circ}$ square.

The luminance levels of the blank square and of the white area surrounding the rivalry targets were $7 \mathrm{ft}$. $-\mathrm{L}$ for the left field and $4 \mathrm{ft} .-\mathrm{L}$ for the right field. Ss viewed the fields through $2 \mathrm{~mm}$ artificial pupils. The distance between pupils and targets was $71 \mathrm{~cm}$. A headand-chin rest restricted head movements.

The test inputs were three white transilluminated $16^{\prime}$ letter forms ( $A, T$, and $U$ ) which were presented in the center of the rivalry targets. Duration of the presentation of the letters was controlled by the tachistoscope system. Neutral density filters controlled luminance.

Design and Procedure. $\quad \mathrm{S}$ had two basic tasks on each trial: (1) To continually indicate the phenomenal suppression and nonsuppression states during rivalry by depressing and releasing a finger-operated key; for the nonrivalry condition $S$ pseudo-tracked (i.e., he generated an imitation observing response which simulated his rivalry alternations). (2) To submit a forcedchoice response to one of the three equally probable letter forms presented.

There were three basic stimulus conditions for each eye: suppression, nonsuppresion, and nonrivalry. Under suppression, the test form was presented when the eye was not phenomenally dominant. Under nonsuppression, the form was presented when the eye was dominant. During nonrivalry, the form was always presented in the field containing the rivalry target.

In preliminary sessions the probability of correct forced-choice recognition of the three equiprobable forms for each eye of each $\mathrm{S}$ was fixed at some value between $50-70 \%$. Duration (which ranged from 35 to $60 \mathrm{msec}$.) and luminance of the forms were manipulated to secure these values, which were determined under the nonrivalry condition. After practice, the recognition thresholds were reasonably stable throughout the experiment. (This general procedure is highly similar to that developed by Charles W. Eriksen; e.g., Eriksen, 1966.)

In a single session the three conditions were run concommitantly for both eyes. For the rivalry conditions each letter was presented an equal number of times to each eye and equally often during suppression and nonsuppression periods in accord with a quasirandom schedule unknown to $S$. For the nonrivalry condition the letters were presented to one eye at a time; suppression and nonsuppression periods were simulated by $S$ with his response key. The order of conditions was counterbalanced over the experiment; 14 sessions 


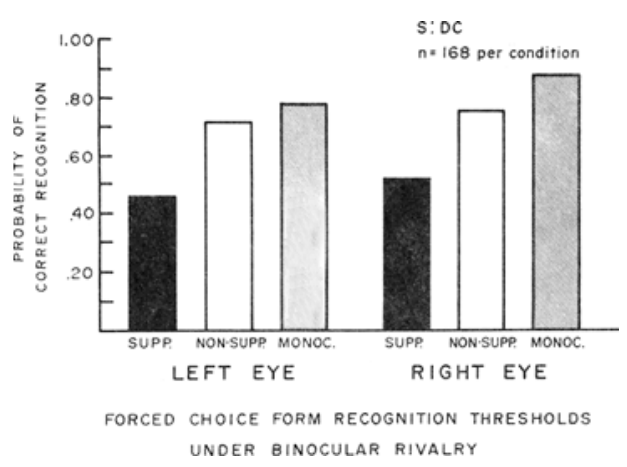

Fig. 1. Mean recognition scores for Subject DC under rivalry suppression and nonsuppression and under a nonrivalry control condition (monoc.).

were run, with 72 trials taken in one session.

\section{Procedure}

For each trial $S$ reported at least one complete cycle of rivalry, after which $E$ connected the output of the response key to the timing and logic units so that the next change of rivalry state initiated a .1 sec. auditory ready signal followed .4 sec. later by the test form. S rested about $15-20 \mathrm{sec}$. between trials.

To control for observation errors or spontaneous changes of state on each trial, $\mathrm{S}$ issued a confirmatory verbal report on his actual rivalry state present at the onset of the test flash. Trials were not recorded for statistical analysis if the confirmatory report and the state indicated by the rivalry tracking switch did not agree. However, the number of disconfirmed trials was quite small.

Ss were trained to assume a high criterion level in reporting rivalry changes; changes of state were reported only when complete dominance or suppression of a target occurred. The durations of suppression and nonsuppression phases for both subjects were approximately equal and on the order of 3-4 sec.

\section{Results}

An analysis of variance was performed on the number of correct responses for each subject and for each eye (the percentages of recognitions for each condition are presented in Figs. 1 and 2). For subject DC, right eye $F=18.79, d f=2 / 26, p<.01$, left eye $F=26.46, d f=$ $2 / 26, \mathrm{p}<.01$; for subject $\mathrm{CM}$, right eye $\mathrm{F}=4.60$, $\mathrm{df}=2 / 26, \mathrm{p}<.05$, left eye $\mathrm{F}=14.03, \mathrm{df}=2 / 26 . \mathrm{p}<.01$. In all cases suppression was significantly lower than nonsuppression or nonrivalry, when assessed by the Newman-Keuls multiple comparison technique with $p=.01$. Additional analyses were made combining the right and left eyes for each subject; interaction effects were absent for both Ss. For subject DC, $F=40.63$, $\mathrm{df}=2 / 26, \mathrm{p}<.01 ;$ for subject $\mathrm{CM}, \mathrm{F}=15.82, \mathrm{df}=2 / 26$. $\mathrm{p}<.01$. Multiple comparisons made after these combined analyses again showed that suppression yielded significantly fewer correct responses than nonsuppression

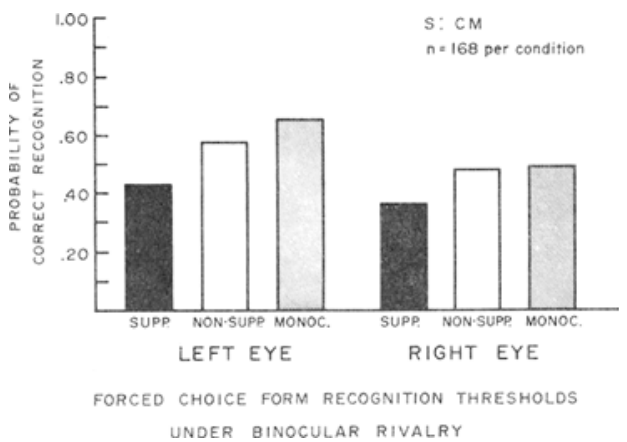

Fig. 2. Mean recognition scores for Subject $\mathbf{C M}$ under rivalry suppression and nonsuppression and under a nonrivalry control condition (monoc.).

or nonrivalry. Nonsuppression and nonrivalry did not differ from each other in any comparison made except for the case of subject DC's right eye, which reached marginal significance $(p<.10$ when analyzed separately). In general, then, form recognition was significantly impaired during suppression for each eye for both subjects, while nonsuppression and nonrivalry conditions were not significantly different from each other.

\section{Discussion}

The increase in recognition threshold for form under the suppression condition is consistent with previous data that has demonstrated an inhibitory effect of suppression upon test inputs. Since the configuration of the rivalry targets differs considerably from that of the test forms, the hypothesis that suppression acts nonselectively upon many classes of test inputs receives further support from the present data.

The absence of significant differences in threshold between nonsuppression and nonrivalry conditions indicates that the nonsuppression state approximates the normal sensitivity level of the visual system. Accordingly, the attenuation found during suppression must represent a reduction in sensitivity rather than a relative change in level. The tendency for the nonrivalry thresholds to be lower than nonsuppression can probably be attributed to the greater demands placed on $S$ when required to report active rivalry.

\section{References}

Eriksen, C. W. Independence of successive inputs and uncorrelated error in visual form perception. J. exp. Psychol., 1966, 72, 26-35.

Fox, R. An analysis of the suppression mechanism in binocular rivalry. Unpublished doctoral dissertation, University of Cincinnati, 1963.

Fox, R. The suppression mechanism in binocular rivalry: movement detection. Paper read at Psychonomic Society meeting, October, 1965.

\section{Note}

1. This research was supported by grant MH-0834 from the U. S. Public Health Service. 